\title{
A voz feminina no poema de Adélia Prado: uma bandeira de luta
}

\author{
Iara Bottan ${ }^{1}$ \\ Bruno Pucci ${ }^{2}$
}

\section{Resumo}

Este artigo se propõe a desenvolver uma interpretação crítica do poema de Adélia Prado, Com Licença Poética, em diálogo com o Poema de Sete Faces, de Drummond de Andrade, e com as reflexões estético-filosóficas de Theodor Adorno, particularmente em sua Palestra sobre Lírica e Sociedade. Entranhar-se na intimidade de seus versos na tentativa de compreender o anúncio do "anjo esbelto" à mulher do século XX, "vai carregar bandeira", é seu desafio primeiro. Observar que a luta das mulheres pela emancipação, pela igualdade de direitos com os homens, se faz intensa e mais do que nunca necessária nos dias de hoje é outra constatação que o poema, como obra de arte viva, transmite, incentiva e indica. Sigamos seus encaminhamentos!

Palavras-chave: Com Licença Poética; Adélia Prado; Emancipação Feminina; Drummond de Andrade; Reflexões Estético-filosóficas.

\section{The female voice in Adélia Prado's poem: a fighting flag}

\begin{abstract}
This article proposes to develop a critical interpretation of Adélia Prado's poem, Com Licença Poética, in dialogue with Drummond de Andrade's Poema de Sete Faces and the aesthetic-philosophical reflections by Theodor Adorno, specially in his Lecture about Lyric and Society. Deepening the intimacy of her verses attempting to understand the "svelte angel's" announcement to the twentieth-century woman, "carry the flag," is her first challenge. To observe that the women's fight for emancipation, for the equality of men's rights, becomes intense and more than ever necessary today is another observation that the poem, as a work of living art, transmits, encourages and indicates. Let us follow your referrals!

Keywords: Com Licença Poética; Adélia Prado; Female Emancipation; Drummond de Andrade; AestheticPhilosophical Reflections.
\end{abstract}

\section{La voz femenina en el poema de Adélia Prado: una bandera de lucha}

\section{Resumen}

Este artículo se propone desarrollar una interpretación crítica del poema de Adélia Prado, con licencia poética, en diálogo con el Poema de Siete Faces, de Drummond de Andrade, y con las reflexiones estético-filosóficas de Theodor Adorno, particularmente en su Conferencia sobre Lírica y Sociedad. Entranse en la intimidad de sus versos en el intento de comprender el anuncio del "ángel esbelto" a la mujer del siglo XX, "va a cargar bandera", es su desafío primero. Observar que la lucha de las mujeres por la emancipación, por la igualdad de derechos con los hombres, se hace intensa y más que nunca necesaria en los días de hoy, es otra constatación que el poema, como obra de arte viva, transmite, alienta e indica. iSigamos sus encaminamientos!

Palabras clave: Com Licença Poética; Adélia Prado; Emancipación Femenina; Drummond de Andrade; Reflexiones estético-filosóficas.

La voix féminine dans le poème d'Adélia Prado: un drapeau de combat

\footnotetext{
${ }^{1}$ Secretaria da Educação do Estado de São Paulo, Piracicaba, SP, iarabottan@hotmail.com

2 Universidade Metodista de Piracicaba, UNIMEP, Piracicaba, SP, puccibru@gmail.com

Periódico Horizontes - USF - Itatiba, SP - Brasil - e019050
} 


\section{Résume}

Cet article propose de développer une interprétation critique du poème d'Adélia Prado, le Com Licença Poética en dialogue avec le poème de Sete Faces, du Drummond de Andrade, et avec des réflexions esthétiques et philosophiques de Theodor Adorno, en particulier dans son exposé sur Lyric et société. Plonger dans l'intimité de ses vers pour tenter de comprendre l'annonce faite par le "svelte ange" à la femme du vingtième siècle, "porte drapeau", constitue son premier défi. Remarque que la lutte des femmes pour l'émancipation, pour l'égalité des droits avec les hommes, devient intense et plus que jamais nécessaire aujourd'hui est un autre constat que le poème, en tant qu'œuvre d'art vivant, transmet, encourage et indique. Suivrons ses références!

Mots-Clés: Le Com Licença Poética; Adelia Prado; Émancipation féminine; Drummond de Andrade; Réflexions esthétiques et philosophiques.

\section{Considerações iniciais}

- A poesia pousa onde Ihe apraz. Tem o dom de espalhar humanidade (Adélia Prado, 2000).

- Só entende aquilo que o poema diz, quem escuta, em sua solidão, a voz da humanidade (Adorno, 2003, p.67).

- Mulheres e homens que amam as mulheres: "ninguém solta a mão de ninguém" (Elianne Brum, 2018).

Este texto é uma tentativa de interpretação do poema Com Licença Poética, de Adélia Prado, uma paráfrase do Poema de Sete Faces, de Carlos Drummond de Andrade. O que nos leva a realizar esta leitura da poeta é a abrangência, a profundidade e a significação que possui sua ode, marcada pelo tom feminino do eu lírico e pelos elementos do campo semântico com o qual Prado constrói e reconstrói o cotidiano e a vida. Um cotidiano revelador da ligação que a escritora estabelece entre o material e o espiritual, o erotismo e a religiosidade, a imanência e a transcendência, o amor espiritual e o amor carnal, definida por ela como a própria condição da literatura.

Em 1973, Adélia enviou seus poemas ao poeta e crítico literário Affonso Romano de Sant'Anna, que os encaminhou a Carlos Drummond de Andrade. Em 1975, Drummond sugeriu à editora Imago a publicação dos poemas, o que resultou no livro Bagagem ${ }^{3}$, que resume, no dizer de Adélia, "aquilo que não posso deixar ou esquecer em casa - a própria poesia" (PRADO, 2000). Em sua crônica no Jornal do Brasil de 09 de outubro de 1975, Drummond apresentava a inédita

\footnotetext{
3 "Bagagem, meu primeiro livro, foi feito num entusiasmo de fundação e descoberta nesta felicidade. Emoções para mim inseparáveis da criação, ainda que nascidas, muitas vezes, do sofrimento. Descobri ainda que a experiência poética é sempre religiosa, quer nasça do impacto da leitura de um texto sagrado, de um olhar amoroso sobre você, ou de observar formigas trabalhando" (PRADO, 1997. p.331).
}

Periódico Horizontes - USF - Itatiba, SP - Brasil - e019050 
Adélia Prado, como a "grande poeta-mulher":

(...) Esse Francisco não para de cativar a gente. Há santos que ficam quietos na bem-aventurança, não descem do altar, só esperam devoção e respeito. 0 Francisco não. Acompanha a gente na cidade (...), ensina cada um a fazer coisas belas, e a amar com sabedoria. Acho que ele está no momento ditando em Divinópolis os mais belos poemas e prosas a Adélia Prado. Adélia é lírica, é bíblica, existencial, faz poesia como faz bom tempo: esta é a lei, não dos homens, mas de Deus (...). (...) Adélia é fogo, fogo de Deus em Divinópolis (ANDRADE, 1975, p.5).

Licença poética solicitada, licença poética concedida. Assim Adélia Prado foi lançada como escritora da Literatura Brasileira e hoje é consagrada. Este poema, objeto de nossa reflexão, é o texto poético com o qual Adélia abre o livro Bagagem. Nosso objetivo é desenvolver uma leitura interpretativa do poema, considerando-o como obra de arte, na busca de compreender a voz feminina sobre as questões existenciais que lhe são próprias, e a possibilidade de essa obra, enquanto um ser vivo, nos revelar ensinamentos, verdades, referentes às tensões sociais e culturais que assolam as mulheres neste momento histórico, cerca de quarenta e cinco anos após o poema ter vindo ao mundo.

Entretanto, é pertinente salientar que nossa leitura não tem a pretensão de abordar as inúmeras análises que a crítica literária e os estudos da Teoria da Literatura tão bem já realizaram e ainda o fazem sobre essa obra. Nosso objetivo é construir uma análise interpretativa do poema, em diálogo com as reflexões estético-filosóficas que Theodor Adorno (1903-1969) nos deixou e, a partir dessa dimensão, trazer uma possível contribuição para além do que já foi contemplado sobre essa obra.

Para Aquino e Pucci (2018, p.1), a obra de arte, na perspectiva de Adorno, é "portadora da tensão entre a realidade e sua negação, constituindo-se como expressão autônoma das contradições históricas do mundo social". Na concepção dos autores, "a imersão na obra de arte contribui para o desenvolvimento de uma consciência crítica do indivíduo, ao percebê-la não como mera expressão do que existe e, sim, como questionamento do existente e de suas possibilidades". Contribui, ainda, "para uma experiência humana significativa, em contraposição ao mero consumo contemplativo e vazio ao qual a indústria cultural do capitalismo tardio a reduziu".

Para Adorno (2011, p.266), "quanto mais o contemplador se entrega tanto maior é a energia com que penetra na obra de arte e a objetividade que ele percebe no interior". Para o 
filósofo, a arte distingue-se da realidade da qual proveio e a análise crítica dessa proveniência só pode ser realizada por meio da reflexão. Isto quer dizer que a contemplação da obra de arte se realiza por meio da análise e da interpretação, ao considerar o tema, a forma, as técnicas de composição, o estilo do autor, o simbólico nela presente, a recriação da aparência da obra, processada pela racionalidade construtiva e pela mimese. Por mimese Adorno entende o "préespiritual" da arte, "aquilo que incendeia o espírito", o que dá vida à obra. Concepção esta que dialoga com a descrição do processo de escrita expresso por Adélia Prado (2000):

Você sente que algo "pede" expressão. Então, é o momento do trabalho concreto de escrever, procurar como dizer aquilo que está pedindo expressão. Num primeiro momento, acredito na inspiração. É o estado e fruição poética que determinada coisa lhe provoca, com o desejo imediato de expressar aquilo. É uma necessidade fatal. O segundo, a escrita propriamente, considero momento de enorme prazer e alegria. É uma coisa fantástica escrever, descobrir sua própria voz. Quem escreve sabe disso.

Escrever o que pede expressão é recriar a realidade, uma realidade concreta, percebida e apreendida ao ser observada, sentida e pensada, num processo de fruição, em que estão tensionados dois movimentos, "um momento no movimento do espírito e um momento do movimento social real" (ADORNO, 2011, p.294). É saber encontrar o termo pertinente para melhor exprimir o que foi intuído, pois este necessita sempre do pensado, do conceito, para que a inspiração não abandone seu criador e se concretize vivamente na linguagem.

Por sua vez, para Adorno, ao tomar um poema lírico como objeto de análise interpretativa, deve-se considerar, inicialmente, duas orientações básicas: 1). 0 procedimento analítico-interpretativo deve ser imanente; os conceitos "não devem ser trazidos de fora às composições líricas, mas sim devem surgir da rigorosa intuição delas mesmas" (ADORNO, 2003, p.67); 2). Na estrutura enxuta da composição lírica, no contexto de sua mais irrestrita individuação, na solidão subjetiva de seus versos, se esconde e se expressa vozes da humanidade, tensões do individual com o social, entrelaçamentos do particular com o universal. É o que nos revela o frankfurtiano na citação a seguir:

A referência ao social não deve levar para fora da obra de arte, mas sim levar mais fundo para dentro dela. É isso o que se deve esperar, e até a mais simples

Periódico Horizontes - USF - Itatiba, SP - Brasil - e019050 
reflexão caminha nesse sentido. Pois o teor [Gehalt] de um poema não é a mera expressão de emoções e experiências individuais. Pelo contrário, estas só se tornam artísticas quando, justamente em virtude da especificação que adquirem ao ganhar forma estética, conquistam sua participação no universal (ADORNO, 2003, p.66).

Essa relação entre o particular e o universal evidencia-se na afirmação de Adélia Prado quando define o processo de sua escrita: "O transe poético é o experimento de uma realidade anterior a você. Ela te observa e te ama. Isto é sagrado. É de Deus. É seu próprio olhar pondo nas coisas uma claridade inefável. Tentar dizê-la é o labor do poeta" (PRADO, 1997, p.331). É, portanto, trabalho do poeta dizer a realidade, uma realidade experimentada, vivida, um eu individual que se constitui historicamente, na relação com outros "eus" individuais, a partir da interação social.

A realidade social é temporal, cronológica e ideológica, em um espaço e tempo determinados, nos quais os indivíduos convivem e se interagem socialmente, constituindo a cultura, a própria vida. Somos seres individuais e coletivos, históricos e sociais, eis a universalidade. Somos universais porque a realidade social se faz presente em nós ao mesmo tempo em que é exterior a nós, mas transparece na expressão íntima de nosso ser, de nossas vivências, de nossos dizeres.

Além disso, segundo Adorno (2003, p.66), “a própria solidão da palavra lírica é prétraçada pela sociedade individualista e, em última análise, atomística, assim como, inversamente, sua capacidade de criar vínculos universais vive da densidade de sua individuação". Um poema lírico, por mais intimista que ele se manifeste em sua composição, é sempre expressão de um acontecimento histórico, elaborado por um poeta que vive suas contradições na realidade social que o cerca, que se utiliza de conceitos e de termos linguísticos específicos de um momento. "Há uma corrente subterrânea coletiva que é o fundamento de toda lírica individual" (ADORNO, 2003, p.77).

Mas, como afirma Adorno em sua Palestra sobre Lírica e Sociedade (2003, p.78), "as considerações de princípios não são suficientes", é preciso concretizar, na análise de poemas, "a relação que o sujeito poético, que sempre representa um sujeito coletivo muito mais universal, mantém com a realidade social que lhe é antitética". Sendo assim, pedimos licença poética para penetrar no poema de Adélia Prado objetivando sua interpretação, na tentativa de fazer uma leitura dos elementos materiais e formais que se interpenetram na composição e ao encontro 
do núcleo temporal da verdade que nele se expressa:

\section{Com licença poética}

Quando nasci um anjo esbelto, desses que tocam trombeta, anunciou:

vai carregar bandeira.

Cargo muito pesado pra mulher, esta espécie ainda envergonhada.

Aceito os subterfúgios que me cabem, sem precisar mentir.

Não sou feia que não possa casar,

acho o Rio de Janeiro uma beleza e

ora sim, ora não, creio em parto sem dor.

Mas o que sinto escrevo. Cumpro a sina.

Inauguro linhagens, fundo reinos

- dor não é amargura.

Minha tristeza não tem pedigree,

já a minha vontade de alegria,

sua raiz vai ao meu mil avô.

Vai ser coxo na vida é maldição pra homem.

Mulher é desdobrável. Eu sou.

(Adélia Prado, 2008, p.9)

Huizinga ressalta que essencialmente a linguagem poética "joga com as palavras". "Ordena-as de maneira harmoniosa e injeta mistério em cada uma delas, de tal modo que cada imagem passa a encerrar a solução de um enigma" (1996, p.148). Nosso eixo interpretativo no texto é a análise do eu feminino, silenciado histórica e socialmente, e que, na voz de muitas escritoras, ecoa como canto de demarcação de um lugar. No caso do eu lírico adeliano, marcando o lugar de mulher e de poeta, neste, como nos demais poemas do livro Bagagem.

A crítica literária e outros tantos estudos apresentam Adélia como aquela que cumpre a sina, a sina de ser poeta, e poeta-mulher, ao mesmo tempo em que apresenta as tensões do ser feminino e suas especificidades diante do masculino. $O$ título do poema, de certa maneira, pode ser entendido no contexto dessa perspectiva: a mulher de uma cidade do interior de Minas Gerais, que tece poesia, se dirige, com reverência e ousadia, ao maior dos poetas brasileiros, daquele momento histórico - década de 1970 --, e solicita-Ihe a bênção e o apoio para expressar não apenas seus versos, suas emoções e experiências individuais, e sim, sobretudo, a nova missão da mulher na sociedade contemporânea; a mulher que solicita a permissão para dialogar com o homem, através da poesia, e, ao mesmo tempo, se contrapõe a ele, nos versos, pela especificidade de gênero, pelos contratempos da submissão histórica, pelas perspectivas de

$$
\text { Periódico Horizontes - USF - Itatiba, SP - Brasil - e019050 }
$$


transformações culturais: Com licença poética! Com licença, poeta!

Essa nova missão da mulher na sociedade contemporânea é anunciada através de expressões individuais e subjetivas, mas ganha uma dimensão objetiva e universal, como o foi o processo de anunciação feito pelo anjo a Maria, de Nazaré, de que ela seria a mãe de Jesus. Neste caso, o anjo se chamava Gabriel, pertencia à ordem dos Arcanjos, como Miguel e Rafael, e se tornou o mensageiro de Deus ao anunciar à Maria sua maternal missão (SÃO LUCAS, 1, 26-38).

No caso de Drummond, do Poema das sete Faces, o anjo que lhe traz a mensagem e como que lhe dá uma ordem -- "Vai, Carlos! ser guache na vida -, não goza dos privilégios dos arcanjos; pelo contrário, trata-se de "um anjo torto, desses que vivem na sombra", um alguém sem prestígio, talvez até um mau conselheiro. "Vai ser gauche na vida!" é mais que uma ordem; para Prado, "é maldição"; é ser estranho, deslocado, diferente, na sociedade; revela os resultados de uma sobrevivência torta, egoísta. Retrata bem o patriarcalismo, o machismo genealógico do homem. Ele tem o anjo que lhe coube pela sua história no mundo ocidental.

Em contraposição ao anjo de Drummond, aquele que participa da anunciação do que a mulher deverá ser, nos versos de Prado, é "esbelto", majestoso como os anjos adultos pintados por Sandro Botticelli (1445-1510) ou por Raffaello Sanzio (1483-1520); anjos "que tocam trombeta", que proporcionam a uma mensagem individual um horizonte infindo, anunciando a todos os ventos algo de fundamental e expressivo para aquela mulher que vem ao mundo na primeira metade do século XX, mas com ressonâncias para todas as outras que virão depois: "Vai carregar bandeira".

Para além, pois, da paráfrase do anjo coxo de Drummond, o anjo esbelto de Adélia é uma analogia da anunciação divina, símbolo de possibilidade de mudanças nos costumes humanos, imagem de um homem que veio ao mundo para trazer a bandeira do amor, do altruísmo, do perdão.

Carregar bandeira, historicamente falando, é uma proposta ousada, que aponta na perspectiva da emancipação feminina, do assumir a condição da mulher em seus direitos e deveres como ser humano, de lutar pela igualdade social dos gêneros.

A proposta do anjo é emancipatória, pois se expressa como símbolo da consciência crítica da realidade social do momento, na perspectiva de dar voz ao feminino que tem desejos, pensamentos, racionalidade e vida próprios. Mas a realização da proposta pelas mulheres é muito difícil nesse momento histórico, anos 1970. E os versos caracterizam com pertinência essa 
realidade: "Cargo muito pesado pra mulher, esta espécie ainda envergonhada".

Há, pois, uma tensão existencial nos versos, que se expressa de forma metafórica e incisiva na viabilização da mensagem do anjo esbelto: "Vai carregar bandeira"! De um lado, como mulher, numa sociedade patriarcal, historicamente dominada pelo masculino, ela é como que obrigada a "cumprir a sina": ser filha, esposa, mãe, dona do lar; às vezes, exercer uma profissão fora de casa - enfim, "aceitar os subterfúgios que lhe cabem, sem precisar mentir".

Por outro lado, ao mesmo tempo, o poema ressalta liricamente a postura corajosa do eu feminino: "Inauguro linhagens, fundo reinos". Ou seja, carregar bandeira é mais que aceitar o papel que a sociedade dominante Ihe atribui, através dos tempos, como mulher, mãe, esposa, "recatada dona do lar"; é ir, individual e coletivamente, além das delimitações impostas arbitrariamente.

A mulher, "esta espécie ainda envergonhada", precisa agora enfrentar o peso de sua condição e marcar o seu lugar, contrariando a educação e as condições sociais que Ihe foram dadas. Cabe então ao eu lírico assumir essa incumbência em seu discurso, cumprir a sina de ser mulher, esposa, filha, mãe, e, ao mesmo tempo, vivenciar a contradição entre essa realidade e sua negação; e assim constituir-se como expressão autônoma das contradições sociais, que, neste caso, se revela na busca pelo seu lugar específico na realidade em que ela atua e vive.

Para Adorno (2003, p.71), “o poema reverbera o desassossego do próprio sujeito". Ao mesmo tempo em que o eu lírico se assume como mulher -- expressa na consciência da designação estereotipada de fragilidade que Ihe foi ditada, como explícita nos versos "cargo muito pesado para mulher", "espécie ainda tão envergonhada", ele também vislumbra a possibilidade de ir além dessa dimensão individual e social. Eis, pois o desassossego! A bandeira nesse sentido é representação da identidade feminina e carregá-la é tomar posse dessa identidade, compreender seu ser e dar voz ao que é, "sem precisar mentir". Um tomar posse que não vislumbra apenas mediar os conflitos de gênero, mas sobretudo reconhecer o seu valor. E, portanto, este é, para nós, o núcleo temporal da verdade desta obra: a consciência crítica sobre a condição feminina e o lugar da mulher na sociedade, revelando ao mesmo tempo um momento no movimento do espírito - nos versos - e um momento do movimento social real. A obra de arte se manifesta, então, como uma mônada, como expressão individualizada das tensões sociais e culturais que acontecem nas relações de gênero da contemporaneidade.

Periódico Horizontes - USF - Itatiba, SP - Brasil - e019050 
Para Moriconi (1998, p.16), mesmo a poesia de Adélia Prado não pretendendo explorar os conflitos de gênero, ao reconhecer seu valor, assume o rompimento com essa tradição, porque coloca "a figura feminina no espaço público" e afirma "sua identidade de forma plena", desvencilhando-se das "amarras do pudor por estereótipos tradicionais de fragilidade, docilidade e domesticidade". De acordo com o autor, a expressão erótica na voz feminina traduz "uma nova subjetividade social", é a celebração do "próprio corpo como signo de diferença na arena pública". A representação, pois, de "carregar bandeira", possui a dimensão de colocar a figura feminina como agente no espaço público.

Para Adélia Prado, a palavra deve ser bela. E por esta razão, diz ela:

Não a sinto como categoria utilitária destinada a prestar tal ou qual serviço. Daí meu incômodo e meu desgosto com a chamada literatura engajada, uma contradição já em termos. A palavra, quando intenciona um resultado prático, uma ação, vira discursivamente política, religiosa, filosófica, panfletária, como ensaio, artigo etc. Deve, evidentemente, possuir a beleza da correção e da clareza. Não mais Ihe será pedido. A palavra literária, pelo contrário, não precisa (até pode) ser "correta" nem clara, mas tem de ser bela (PRADO apud MOREIRA, 2000, p.86-7).

E acrescenta que "se beleza for considerada uma função, estará aí a única coisa que se pede à literatura". E sendo a verdadeira literatura obra de arte, "será ontologicamente crítica (engajada) e revolucionária". Por esta razão, "dispensa da parte do autor a preocupação de sintonizá-la com o que quer que seja" (PRADO apud MOREIRA, 2000, p.86-7). Temos então a arte como negação de tudo que lhe é externamente imposto - e por isso as obras "têm sua grandeza unicamente em deixarem falar aquilo que a ideologia esconde" (ADORNO, 2003, p.68). Nessa negação, o eu lírico adeliano, ao aceitar os subterfúgios que lhe cabem, desvencilha-se dos estereótipos atribuídos à mulher e distancia-se da mera e comum existência.

Neste poema, o parto também assume o sentido de nascimento da mulher-poeta: "ora sim, ora não, creio em parto sem dor. Mas o que sinto escrevo". O eu lírico nesse jogo de palavras nos diz do nascimento de cada nova mulher que se inaugura no exercício da sua condição e de suas transformações - as metamorfoses experimentadas ora diante da dor ora da alegria e das tensões em cada uma de suas fases: a filha, a esposa, a mãe, a dona de casa, a profissional. Esse cotidiano feminino, em contraposição ao exercício dos papéis que the foram atribuídos e, 
também, que ela foi conquistando socialmente, agora está compartilhado, por meio da escrita, com sua outra condição - o ser poeta. Diferentes condições que se interpenetram e se complementam na caracterização da mulher contemporânea.

Nesse sentido, consideramos também a poesia como um dos fundamentos da metamorfose do eu lírico adeliano, isto porque, para Adélia, a poesia "alimenta, dá significação, sentido à vida" (PRADO, 2000). A partir de uma observação dialética, a expressão "fundo reinos" simboliza a contraposição com o reino propagado pelos homens, em que os desejos da mulher e da carne são considerados vício e libertinagem. Para Adélia os desejos do corpo são divinos, porque o corpo é imagem e semelhança de Deus. Como se vê, sua dimensão religiosa e cristã se manifesta intensamente em seus dizeres. Outrossim, a expressão "inaugurar linhagens" está muito além da maternidade, está na educação do eu feminino para compreensão de seu próprio corpo, desejo e sexualidade como expressões do sagrado, como direito, como exercício de ser.

No poema, o reino que se funda e a linhagem que se inaugura constituem a própria experiência humana do real, que está em corporificar o feminino. Entendemos esses conceitos como a experiência do real em sua concretude, e, portanto, em sua dimensão social. No poema Com Licença Poética, a dimensão social da mulher é levada para dentro da obra de arte. "Isso mostra que em cada poema lírico devem ser encontrados [...] os sedimentos da relação histórica do sujeito com a objetividade, do indivíduo com a sociedade" (ADORNO, 2003, p.72).

Há também no poema um afastamento explícito entre os conceitos de dor e de amargura: “-- dor não é amargura”. A dor é sentida como resultado de uma situação que as peripécias da vida impõem a partir das tensões cotidianas que envolvem o sujeito particular; tem ela, pois, uma dimensão ativa, propulsora, pois evoca a resistência, a luta para superá-la. A amargura já surge como padecimento moral, diante de uma realidade que nos devora, e frente à qual nos submetemos de certa forma passivamente. Ambas compõem o panorama antagônico social que envolve a mulher, e também o homem, em suas lutas pelo vir-a-ser.

Nesta relação simbólica expressa no texto, "dor não é amargura", a tristeza do eu lírico não tem pedigree, é parte do sujeito, do indivíduo particular, não há lastros de ancestralidade. Entretanto, na expressão "já a minha vontade de alegria, sua raiz vai ao meu mil avô", percebemos que é a vontade, a alegria de viver, que impulsiona o eu lírico à sua existência e mais ainda: esse querer a alegria, lutar pela felicidade, vem de uma linhagem genealógica, que por 
laços de sangue representa todas as mulheres que compõem a sua história de luta, da qual é herdeira e remete ao próprio início da criação.

Considerando a religiosidade presente nos textos adelianos, vislumbramos a menção a Adão, como pai da humanidade e a Deus como o criador do homem e da mulher; e observamos também uma crítica à realidade social: a origem do homem e da mulher vem de Deus, o perfeito, mas as ações são dos homens, marcadas pelo livre-arbítrio; e a responsabilidade de se viver como seres solidários, parceiros e conquistar a alegria da vida também se inserem neste ideário.

Notemos a palavra vontade, que expressa desejo, querer, a negação do ter. Se alguém quer algo é porque não o tem; revela não possuir ainda o direito e, ao mesmo tempo, a necessidade de um movimento de conquista. Vemos aqui outro estado de negação do eu lírico, uma negação da realidade que lhe é imposta, no caso, a amargura. A obra de arte possui uma linguagem própria, é viva e como crítica social também desmitifica o ideário de que a alegria é um direito; ela é antes de tudo uma conquista. Isto significa que possuir a alegria é resultado das ações dos sujeitos.

E aqui, mais uma vez, o eu lírico individual, subjetivo, carrega em seus termos o eu feminino real e social, coletivo e universal.

Retomando a metáfora "vai carregar bandeira", entendemos que essa missão, como vimos, diz respeito à realização do eu feminino, na tensão e na composição com o eu masculino, na tentativa de encontrar o mais plenamente possível a "vontade de alegria" no relacionamento entre os seres humanos em todas as dimensões do viver em sociedade.

Prado, em diversas entrevistas apresentou sua concepção de feminino e de masculino, como a que defendeu no Programa Roda Viva, da TV Cultura, em 1994 e que gerou ambiguidades, em se considerando o momento histórico de tal pronunciamento:

O feminino... assim como o ato criador é masculino, para mim, eu sinto as coisas assim, o papel do feminino é o papel do segundo lugar, é o do segundo, é o do serviço, do anonimato mais perfeito. É isso que para mim é o feminino. É a permissão para que o homem aconteça. É que, no caso, num sentido muito profundo mesmo. Sem isso, se nós, mulheres, aqui no caso, que somos até aparentemente, externamente mulheres, se esse feminino não se realizar em nós, da ordem espiritual e psicológica, o homem que está do meu lado não acontece. Porque há uma - como é que se fala? -, uma diluição dos papéis. Eu acredito que há um papel feminino, sim, e que é o papel do serviço. Agora, é muito fácil confundir o papel do serviço com escrava, doméstica etc, como

Periódico Horizontes - USF - Itatiba, SP - Brasil - e019050 
confundir aquilo que eu disse, que o ato criador é masculino, [achando que] é macho. É a mesma confusão que se faz (PRADO, 1994).

Na concepção de Adélia Prado o feminino tem o papel do segundo lugar, do serviço, do anonimato. Não um segundo lugar de desprestígio, ressalta ela, ao contrário, é consciente, intencional, em que compreende a condição do masculino e para que ele se realize, o feminino precisa se colocar no anonimato. Adélia, em diferentes momentos é questionada sobre esse posicionamento, cabível no contexto da ideologia machista predominante na cultura brasileira e também no interior de uma postura católica tradicional; mas não cabível no contexto das lutas pelos direitos sociais e de gênero das mulheres na contemporaneidade. E seus argumentos na justificativa da afirmação do segundo lugar da mulher, na relação social, continuam ambíguos e não pertinentes pela posição social e pelo prestígio literário que seus poemas e prosas ocupam na realidade cultural contemporânea.

Mas aqui percebemos um fenômeno singular no interior do poema de Adélia, que nos causa estranheza e, ao mesmo tempo, admiração. Trata-se da autonomia da obra de arte; esta é, ao mesmo tempo, resultado da racionalidade construtiva de um ator, mas nem sempre expressa fielmente aquilo que o autor pensa ou aquilo que o autor teve intenção de dizer. Uma obra de arte ganha vida própria quando cai no mundo e fala com a própria boca. Adorno já tinha nos advertido sobre esse fenômeno estético: "O caráter linguístico da arte leva à reflexão sobre o que na arte fala; eis o seu verdadeiro sujeito, e não o que a produz ou a recebe" $(2011$, p.254).

Nessa perspectiva, contemplamos a existência de uma tensão entre o testemunho de Adélia na entrevista de Roda Viva e a dimensão de ser mulher que o eu lírico feminino do poema anuncia. Na entrevista, Adélia coloca a mulher num papel subalterno (segundo lugar), a serviço da fragilidade do homem, para que ele se complemente como ser social. Mas no poema, não. Em Com licença poética, predominam as dimensões de autonomia e de solidariedade da mulher. O poema destaca a intencionalidade do eu feminino que cumpre a ordem do anjo esbelto, de carregar sua bandeira de luta, de emancipação, de busca de sua maioridade. No campo lírico prevalece o pronome de primeira pessoa do singular, que assume uma dimensão de universalidade; a poesia vai além de sua criadora.

Vislumbramos, pois, o ato de se desdobrar - "Mulher é desdobrável. Eu sou" -- pela lógica da negatividade, uma vez que etimologicamente o prefixo des é um prefixo de negação, de oposição. Sendo assim, o eu lírico adeliano se manifesta publicamente como o sujeito que não 
se dobra, que, apesar das limitações históricas, enfrenta as batalhas e está disposto a construir um mundo mais humano e solidário, em pé de igualdade e de fraternidade com o homem. Adélia Prado, enquanto poeta, enquanto mulher, através do eu lírico em seus versos se faz presente na luta das mulheres pela emancipação social e é uma das representantes dessa batalha. Ela realiza em seu poema aquilo que Theodor Adorno destacava no artista: Este, "portador da obra de arte, não é apenas aquele indivíduo que a produz, mas sim torna-se o representante, por meio de seu trabalho e de sua passiva atividade, do sujeito social coletivo" (2003, p.164).

E o poema termina seus versos libertários, não apenas destacando a dimensão "desdobrável" e de luta da mulher pelos seus direitos sociais; não apenas colocando-se à disposição para, junto com as mulheres e com todos os envolvidos nessa luta, carregar a bandeira - "Mulher desdobrável. Eu sou"; ele também toma posição contra o egoísmo, a dominação, contra a "maldição" do homem em relação à mulher através dos tempos - "Vai ser coxo na vida é maldição pra homem". Esse questionamento profundo do eu lírico, ao mesmo tempo que é uma análise radical do que foi e do que tem sido a exploração da mulher em nossa realidade social, é igualmente um convite expressivo aos homens para superarem essa "maldição", que pesa historicamente sobre ele e, junto com as mulheres, inclusive com as mais submissas e dobráveis, participarem da luta pelos direitos de todos os seres humanos.

Se este poema já se apresentava como uma bandeira de luta nos anos 1970, quando veio à luz, ele, como um ser vivo, se manifesta mais radical e expressivo nos dias de hoje, em que a sociedade brasileira, através dos movimentos sociais, da utilização dos meios de comunicação e das redes sociais, está, em parte significativa, se conscientizando dessa "maldição" e denunciando as humilhações sofridas na contemporaneidade pelas mulheres.

Alguns dados estatísticos nos apavoram sobre a realidade da violência contra elas, em pleno século XXI. O Brasil tem aproximadamente 207.661 milhões de habitantes, segundo os dados da projeção feitos pelo IBGE para o ano de 2017. As mulheres são a maioria: 51,5\% da população: 106.945 milhões; os homens, 48,5\%: 100.716 milhões. Porém, em termo de salários, as mulheres ganham menos do que os homens em todos os cargos, conforme aponta a pesquisa salarial da Catho que avalia 8 funções, de estagiários a gerentes ${ }^{4}$. No magistério, a situação não

\footnotetext{
4 In: https://g1.globo.com/economia/concursos-e-emprego/noticia/mulheres-ganham-menos-do-que-os-homens-emtodos-os-cargos-diz-pesquisa.ghtml: Acesso em 30/11/2018.
}

Periódico Horizontes - USF - Itatiba, SP - Brasil - e019050 
é diferente: cerca de 2,2 milhões de professores lecionam do Fundamental I ao Ensino Médio. Destes, 1,8 milhões são mulheres. No ensino pré-escolar e fundamental, as professoras informaram receber $\mathrm{R} \$ 1.258,67$, e os professores, $\mathrm{R} \$ 1.685,55$. No ensino médio, docentes do sexo masculino recebiam $\mathrm{R} \$ 2.088,56$, e do feminino, $\mathrm{R} \$ 1.822,66$ (dados de 2017 ) $^{5}$.

O site Violência contra as Mulheres nos traz igualmente dados atuais e alarmantes sobre a situação de violência contra as mulheres: segundo pesquisas divulgadas em 2018, o Brasil registrou 13 mulheres assassinadas por dia e a casa da vítima como local mais perigoso, onde os crimes mais acontecem. Isso representa uma taxa de 4,5 homicídios para cada 100 mil brasileiras; a taxa de homicídios é maior entre as mulheres negras $(5,3)$ do que entre as não-negras $(3,1)$ uma diferença de $71 \%{ }^{6}$

Por outro lado, é mais visível a organização de entidades sociais que se envolvem na luta pela igualdade de direitos das mulheres em nossa sociedade ainda predominantemente machista. Destacamos o Movimento Feminista Brasileiro, sua bandeira pela igualdade de direitos, oportunidades e tratamento entre homens e mulheres e as questões importantes de atuação desse movimento, entre elas: o fim da desigualdade salarial entre homens e mulheres; igualdade da participação das mulheres no cenário político do país, tanto na ocupação de cargos políticos como na tomada de decisões; combate aos diferentes tipos de assédio, como o moral e o sexual; fim da violência contra a mulher: das violências dentro de relacionamentos, violência sexual, assédio moral, violência obstétrica, dentre outras ${ }^{7}$.

Ao mesmo tempo, a "governamentalidade" política que nos administrará nos próximos 4 anos se apresenta mais hostil e preconceituosa em relação à mulher, aos negros, aos membros da LGBT.

Que esse poema escrito nos anos 1970 e que contém em suas entranhas uma bandeira de luta do eu feminino na busca de sua identidade e de sua autodeterminação, possa inspirar e ser um instrumento de práxis social e política não apenas das mulheres, mas de todos aqueles que acreditam na igualdade das pessoas, seja de que gênero forem, e lutam por um mundo mais humano, menos violento, mais fraternal, e com mais "vontade de alegria".

\footnotetext{
${ }^{5}$ Cf. http://inep.gov.br/resultados-e-resumos; e http://www.vermelho.org.br/noticia/308543-1. Acesso em 21/08/2018

${ }^{6}$ https://dossies.agenciapatriciagalvao.org.br/violencia-em-dados/. Acesso em 30/11/2018.

${ }^{7}$ https://www.todapolitica.com/movimento-feminista/. Acesso em 30/11/2018.
} 


\section{Referências}

ADORNO, T. W. Palestra sobre lírica e sociedade. In: ADORNO, T. W. Notas de literatura I. Trad. Jorge de Almeida. São Paulo: Editora 34 / Livraria Duas Cidades, 2003, p.65-90.

ADORNO, T. W. Teoria estética. Trad. Artur Morão. Lisboa: Edições 70, 2011.

ANDRADE, C. D. De animais, santo e gente. Rio de Janeiro: Jornal do Brasil, Caderno B, 1975, p.5. Disponível em:

https://news.google.com/newspapers?nid=0qX8s2k1IRwC\&amp;dat=19751009\&amp;printsec =frontpage\&amp;hl=pt-BR

AQUINO, L. C. A.; PUCCI, B. Amor e enigma em Drummond de Andrade: ensaio de interpretação, 2018, inédito.

HUIZINGA, J. Homo ludens: o jogo como elemento da cultura. 4. ed. Trad. João Paulo Monteiro. São Paulo: Perspectiva, 1996.

MOREIRA, U. Adélia Prado: uma poética da casa. In: Revista UniLetras. v.22, n.2. Ponta Grossa: Editora UEPG, 2000. p. 81-103.

MORICONI, I. Pós-modernismo e volta do sublime na poesia brasileira. In: PEDROSA, C.; MATOS, C.; NASCIMENTO, E. (org.). Poesia hoje. Niterói: Ed.UFF, 1998, p.11-26.

PRADO, A. Entrevista. In: Programa Roda Viva. Memória Roda Viva, 5/9/1994. Disponível em: http://www.rodaviva.fapesp.br/materia/716/entrevistados/adelia_prado_1994.htm

PRADO, A. Minha poesia. In: Revista Poesia Sempre, n.8, jun. 1997, p.231.

PRADO, A. Entrevista. In: Cadernos de Literatura Brasileira - Adélia Prado. São Paulo: Instituto Moreira Salles, 2000, p.21-39.

PRADO, A. Bagagem. 27. ed. Rio de Janeiro: Record, 2008.

SÃO LUCAS, Evangelho de. In: Bíblia Sagrada: edição pastoral. Trad. Euclides M. Balancin e Ivo Storniolo. São Paulo: Edições Paulinas, 1990, p.1310, cap.1, Vers.26-38.

Recebido em abril de 2019.

Aprovado em outubro de 2019.

Periódico Horizontes - USF - Itatiba, SP - Brasil - e019050 